\title{
The relationship between locus of odor cues and double-alternation responding in the rat
}

\author{
ROBERT E. PRYTULA \\ Middle Tennessee State University, Murfreesboro, Tennessee 37130 \\ and \\ STEPHEN F. DAVIS \\ Austin Peay State University, Clarksville, Tennessee 37040
}

\begin{abstract}
In two experiments, rats traversed a runway in the presence of odor cues from odor-donor rats (stimulus odor). These odors were established in the start and run sections of a runway. As in previous work, these odors were shown to be influential determinants of behavior There is an indication that odors of reward and nonreward may be different for different rats, and that these different odors can be used to form complex discriminations.
\end{abstract}

Research on the olfactory control of behavior of rats in a standard laboratory apparatus, the enclosed runway, has indicated a dual role for apparently exuded odors on rewarded and nonrewarded trials. First, such odors may be used as discriminative stimuli by subsequent subjects. It has been shown that rat subjects use such odors as cues to learn such behaviors as: (a) appropriate double-alternation responding (Bloom \& Phillips, 1973; Davis, Prytula, Harper, Tucker, Lewis, \& Flood, 1974; Ludvigson \& Sytsma, 1967; Prytula \& Davis, 1974; Seago, Ludvigson, \& Remley, 1970, (b) appropriate singlealternation responding (Amsel, Hug, \& Surridge, 1969), and (c) appropriate T-maze responding (Morrison \& Ludvigson, 1970). The picture that emerges from these experiments is that an odor exuded by one rat, primarily on frustrative or nonrewarded trials, serves as a discriminative cue for rats run subsequently. Second, odor cues may serve to elicit unconditioned approach responses (Mellgren, Fouts, \& Martin, 1973) or avoidance responses (Collerain \& Ludvigson, 1972; Wasserman \& Jensen, 1969). In these situations, odors have not functioned as discriminative cues in the usual sense, but have produced response facilitation (approach) or response suppression (avoidance). Odor cues have been implicated in the partial reinforcement extinction effect (Davis, 1973; Prytula, Bridges, Anderson, \& Hayes, 1972), the pseudo-extinction effect (Wasserman \& Jensen, 1969), the depression effect (Davis \& Ludvigson, 1969), and the latent extinction effect (Pratt \& Ludvigson, 1970).

This research was supported by a Faculty Research Grant from Middle Tennessee State University to the first author and a Tower Fund Research Grant from Austin Peay State University to the second author.
The present experiments were designed to follow up previous investigations of, and to test the limits to which odors generated by goal events can control the behavior of, conspecifics. In particular, we investigated double-alternation responding in relation to odors established in different parts of an enclosed apparatus (i.e., start, run, and goal segments).

\section{EXPERIMENT I}

Recently, Prytula and Davis (1974) showed that, by placing odor-donor rats in the startbox of a straight alley, the running behavior of other rats would be differentially affected in the various segments (e.g., start vs. goal) of the apparatus. In the first phase of their experiment, the placement of the donor rats on a double-alternation schedule of reward and nonreward affected the behavior of rats run subsequently: the rats that ran in the alley displayed appropriate double-alternation patterning in all segments of the runway. In previous research (e.g., Ludvigson, 1969; Ludvigson \& Sytsma, 1967), the patterning had been limited to the goal segment. However, when in the Prytula and Davis experiment, the odor-donor schedule was changed so that it correlated negatively with the reward schedule of the run subjects, an immediate and pronounced disruption of the double-alternation performance occurred in all segments of the runway. While this disruption continued over many trials in the start and run measures, appropriate double-alternation responding was eventually restored in the goal segment. This most likely occurred because the subjects were run as a squad, and all received Trial 1 of the doublealternation sequence before Trial 2 was run and so on. Hence, the odor cues exuded by the rats run 
Table 1

Relationship Between Odor-Donor and Run Subject Reinforcement (R)/Nonreinforcement (N) Schedules: Experiment I

\begin{tabular}{lcccc}
\hline & $\begin{array}{c}\text { Phase I } \\
\text { (positively } \\
\text { correlated) }\end{array}$ & $\begin{array}{c}\text { Phase II } \\
\text { (first four trials } \\
\text { positively } \\
\text { correlated) }\end{array}$ & $\begin{array}{c}\text { Phase III } \\
\text { (last four trials } \\
\text { positively } \\
\text { correlated) }\end{array}$ & $\begin{array}{c}\text { Phase IV } \\
\text { (negatively } \\
\text { correlated) }\end{array}$ \\
\hline $\begin{array}{l}\text { Odor-Donor } \\
\text { Run Subject }\end{array}$ & RRNNRRNN & RRNNNNRR & NNRRRRNN & NNRRNNRR \\
\hline
\end{tabular}

early on a trial were picked up by animals running to the same reward condition later in the sequence.

Experiment I was designed to investigate the effect(s) of partially correlating the double-alternation reinforcement schedules of the odor-donor and run subjects. For example, the first four trials for the odor-donor subjects might be negatively correlated with the first four trials of the run subjects, while the last four trials in the sequence would be positively correlated. In order to balance the correlations of the various components of the schedules, the experiment was divided into four phases. The specific relationships are shown in Table 1.

\section{Method}

Subjects. Twenty-two 90-day-old male albino rats purchased from the Holtzman Co., Madison, Wisconsin, served as subjects. One week prior to pretraining, all subjects were placed on a fooddeprivation schedule which maintained them at $85 \%$ free-feeding body weight for the duration of the experiment. Maintenance of the deprivation schedule took place after the daily experimental session. Water was continuously available in the home cage.

Apparatus. The apparatus consisted of a single straight runway $(11.4 \mathrm{~cm}$ wide $\times 12.7 \mathrm{~cm}$ high), having a gray startbox $(28.1 \mathrm{~cm})$, black run section $(91.4 \mathrm{~cm})$, and a black goalbox $(30.5 \mathrm{~cm})$. Masonite guillotine doors separated the startbox and goalbox from the run section. Start, run, and goal times, produced by the activation of a microswitch located on the start door and the interruption of a series of photoelectric cells (located $15.2 \mathrm{~cm}$, $92.4 \mathrm{~cm}$ and $116.8 \mathrm{~cm}$ beyond the start door, respectively) were recorded on all trials. A plastic receptacle recessed into the end wall of the goalbox served as the goal cup. A thin sheet of transparent plastic covered the top of the alley to prevent odors from dissipating.

Procedure. Two equal-sized groups, Run and Odor-Donor, were randomly formed prior to pretraining. Each subject was assigned a permanent number (1-11) within his respective group. During pretraining, which began 4 days before Phase 1 , all rats were handled and tamed (Days 1-2), and habituated to the 500-mg reward pellets in the home cage (Days 1-4). On Days 3 and 4 each Run subject received a 5-min exploration period in the unbaited apparatus. The Odor-Donor subjects were handled on these days.

During all four phases of the experiment proper, each rat received eight trials, four reward $(R)$ and four nonreward $(N)$, per day with all rats receiving Trial 1 before Trial 2, etc. The procedure for running a trial was as follows: The appropriate OdorDonor subject (e.g., Odor-Donor 1 was used with Run Subject 1) was removed from the home cage and placed directly into the startbox. The Odor-Donor rat was removed as soon as the reward (one 500-mg Noyes pellet) was consumed (R trials), or a 30-sec confinement period had elapsed ( $\mathrm{N}$ trials), and then the appropriate Run subject was immediately placed into the startbox. After a 10-sec confinement period, the Run subject was allowed to trave:se the runway. Reward and nonreward events were identical ior Odor-Donor and Run subjects. Phase 1 was 12 days
(96 trials) in length, and Phases 2-4 were each 5 days (40 trials) long (see Table 1 for trial sequences during Phases 2-4). The order for running the Odor-Donor/Run subject pairs was randomized daily.

\section{Results and Discussion}

Mean start, run, and goal speeds (meters/sec) for the Run subjects during Phase 1 are shown in Figure 1. For purposes of graphical presentation and analysis, the speed scores for the 8-trial, doublealternation sequence were combined in the following manner: The first two trials were averaged to yield an $R_{1}$ composite score, the next two trials were averaged to yield an $N_{1}$ composite score, and so forth. As can be seen from Figure 1, appropriate patterning (i.e., fast on $R$ trials, slow on $N$ trials) developed in all measures during Phase 1. A Subjects by Treatments by Treatments analysis of variance performed on the data from the last 4 days of Phase 1 (the point at which patterning appeared to

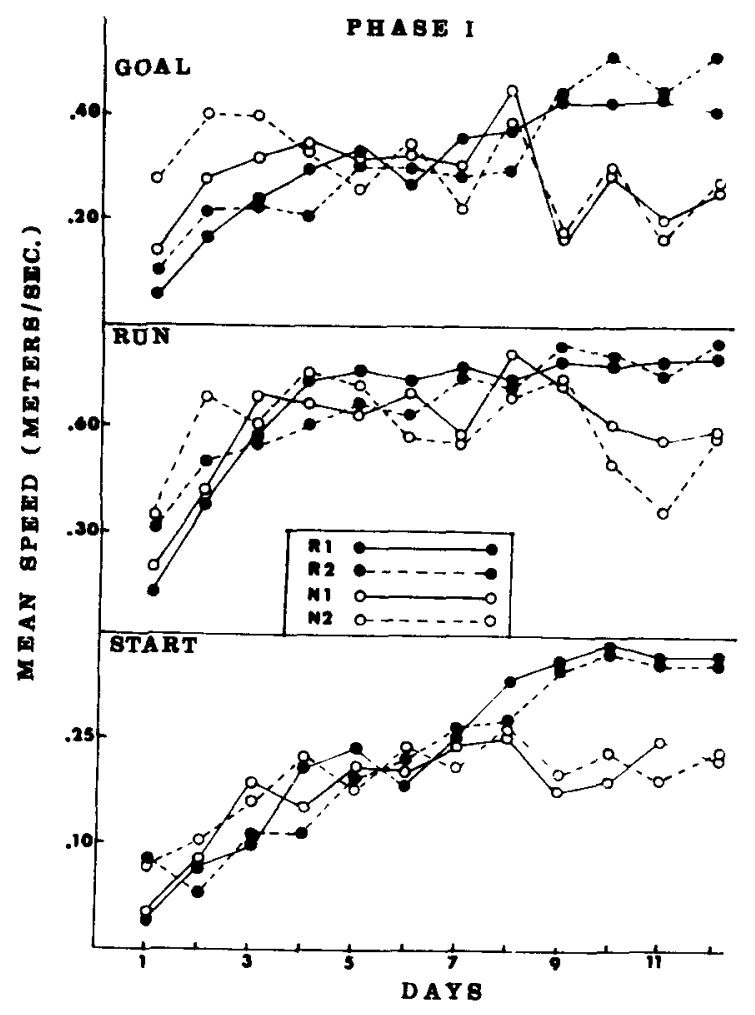

Figure 1. Mean speeds (meters/sec) during Phase 1, Experiment 1 . 


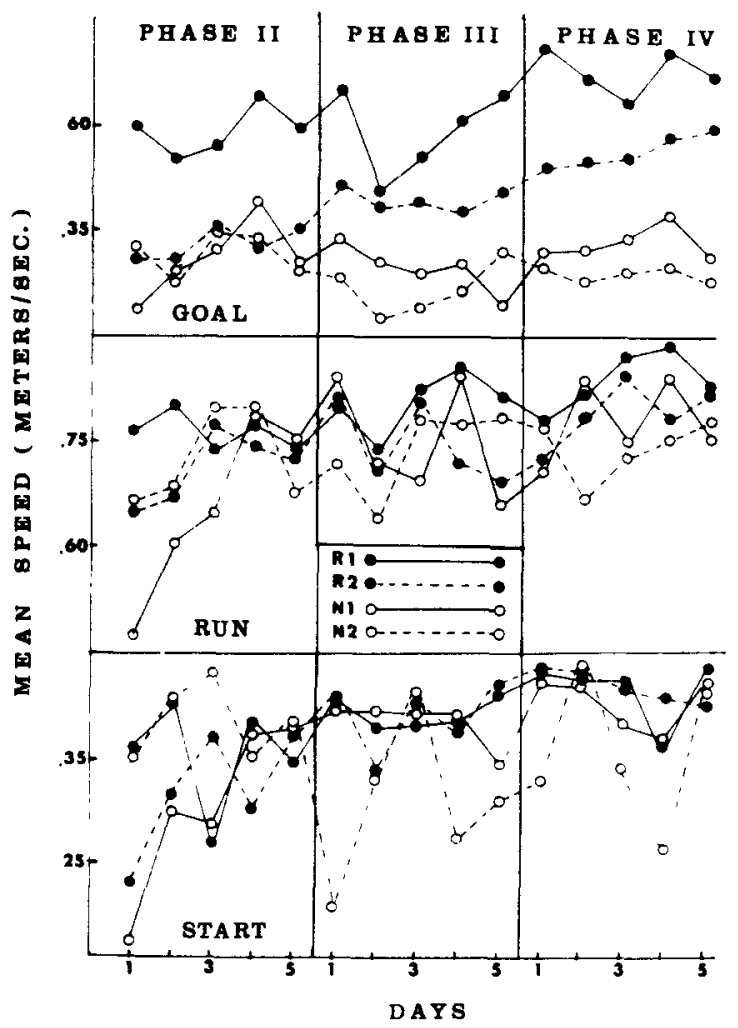

Figure 2. Mean speeds (meters/sec) during Phase 2-4, Experiment 1.

have developed in all measures) indicated that the $\mathrm{R}$ vs. $\mathrm{N}$ factor was significant in all three measures [start, $\mathrm{F}(1,70)=6.74, \mathrm{p}<.01$; run, $\mathrm{F}(1,70)=4.27$, $\mathrm{p}<.05$; and goal, $\mathrm{F}(1,70)=7.36, \mathrm{p}<.01]$. Additionally, the R-N Days interaction was significant in the run measure $[F(3,70)=3.17, p<.05]$. Subsequent analysis of this interaction using Tukey's (a) procedure indicated that a significant $\mathrm{R}$ vs. $\mathrm{N}$ difference $(\mathrm{p}<.05)$ existed at Days $10-12$ of Phase 1 .

Figure 2 presents the mean speeds (meters $/ \mathrm{sec}$ ) for the Run subjects during Phases 2-4. No difference was significant in this phase. However, analyses of the data from Phases 3 and 4 indicated that the $R$ vs. N factor was again significant in the goal measure during both phases [Phase $3, F(1,90)=7.16, p<.01$; Phase $4, F(1,90)=9.52$, $p<.01$, but was not significant in the start and run measures. The R-N by Trials interaction was significant in the start measure during Phases 3 and 4 [Phase 3, $F(4,90)=2.76$, $\mathrm{p}<.05$; Phase $4, \mathrm{~F}(4,90)=2.63, \mathrm{p}<.05$ ]. Through the use of Tukey's (a) procedure it was found that a significant $\mathrm{R}$ vs. $\mathrm{N}$ difference $(\mathrm{p}<.05)$ existed at Days 1, 4, and 5 of Phase 3 and at Days 1 and 4 of Phase 4. Further inspection (t tests) indicated that this effect was primarily attributable to significantly slower responding on the last $\mathbf{N}$ trial of the day $(p<.05)$. This suggests that the next to the last $N$ trial had possibly become a signal for "time out" from reinforcement to the Run subjects during these phases. The double-alternation patterning established in all measures by the run subjects during Phase 1 (see Figure 1) corroborates earlier findings (Davis, et al., 1974; Prytula \& Davis, 1974). However, when the last four trials of the OdorDonor schedule were negatively correlated with those of the Run schedule (Phase 2), a pronounced disruption in performance was shown by the Run subjects (see Figure 2). Initially (i.e., Day 1, Phase 2), the Run subjects relied upon the cue predictability that had been established in Phase 1. Thus, it can be seen that $\mathbf{R}_{2}$ speeds (now preceded by $\mathbf{N}$ donors) were initially depressed, and $N_{2}$ speeds (now preceded by $\mathbf{R}$ donors) were initially elevated. Following this initial reaction, speeds, especially those in the start and run measures, increased on all trials and nondifferential responding was shown. This nondifferential responding persisted in the start and run segments through Phases 3 and 4, indicating that once the predictability of the Odor-Donor cue was eliminated the Run subjects stopped using it as a discriminative stimulus.

On the other hand, the predictability of the odor cues emitted in the goalbox by the Run subjects themselves should not have been influenced by manipulation of the Odor-Donor schedule during Phases 2-4. Therefore, disruption of performance in the goal measure should not be as great as that in the start and run measures. It can be seen in Figure 2 that the shift in the Donor schedule did produce a temporary disruption in goal-measuring performance during Phase 2, but that patterning was reestablished during Phases 3 and 4.

\section{EXPERIMENT II}

Having shown in Experiment I that donor-exuded odors are effective in determining the performance of the Run subject when they are presented at the onset of the instrumental response, the second experiment investigated the role and effectiveness of such cues presented after the response has been initiated. The locus of odor-cue infusion was moved from the start box (Experiment I) to the midpoint of the run section in Experiment II.

\section{Method}

Subjects. Twenty-two 90 -day-old male albino rats purchased from the Holtzman Co., Madison, Wisconsin, served as subjects. Deprivation and maintenance procedures identical to those employed in Experiment I were used.

Apparatus. The apparatus used in Expermment I was also used in Experiment II. In addition, a flexible plastsc box $(9.5 \mathrm{~cm}$ wide $\times 10.4 \mathrm{~cm}$ high $\times 18.6 \mathrm{~cm}$ long) with a screen-wire floor was used for the odor-donor placements.

Procedure. The formation of groups, numbering of subjects within each group, pretraining procedures, and number of trials 


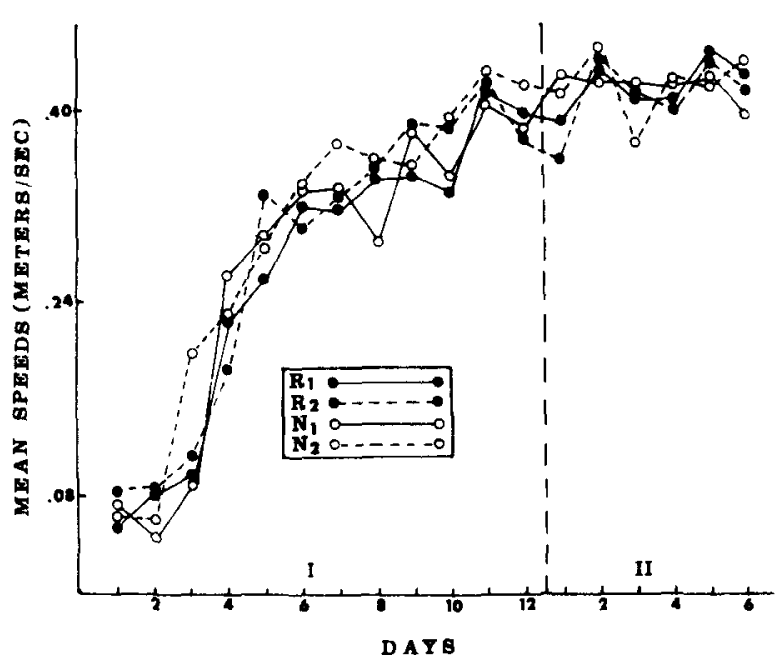

Figure 3. Mean start speeds (meters/sec), Experiment II.

per day were the same as those used in the first study. Experiment 11 consisted of two phases: Phase 1, double-alternation schedules for Run and Odor-Donor subjects positively correlated; Phase 2, double-alternation schedules negatively correlated.

The procedure for running a trial was essentially that of Experiment I, except that the Odor-Donor rat was placed into the plastic box, which, along with the appropriate reward or empty goal cup, was in turn placed in the middle $15.6 \mathrm{~cm}$ of the run section. The Odor-Donor rat and plastic box were both removed from the apparatus as soon as the reward (one 500-mg Noyes pellet) was consumed ( $R$ trials) or a 30 -sec period had elapsed ( $N$ trials). Once the Odor-Donor rat had been removed, the appropriate Run subject was placed into the startbox and, after a 3 -sec wait period, allowed to traverse the runway. Phases 1 and 2 were 96 trials ( 12 days) and 48 trials (6 days) in length, respectively. The order for running the subject pairs was randomized daily.

\section{Results and Discussion}

Figures 3-5 present the mean start, run, and goal speeds (meters/sec) for the Run subjects during Phases 1 and 2.

The Phase 1 analyses were performed on the data from Days 9-12 (the point in training at which

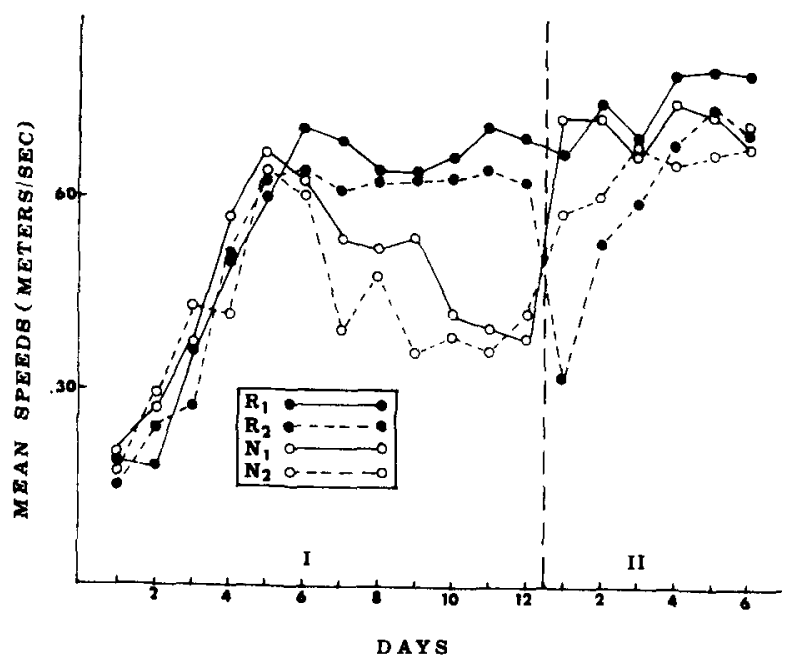

Figure 4. Mean run speeds (meter/sec), Experiment II.

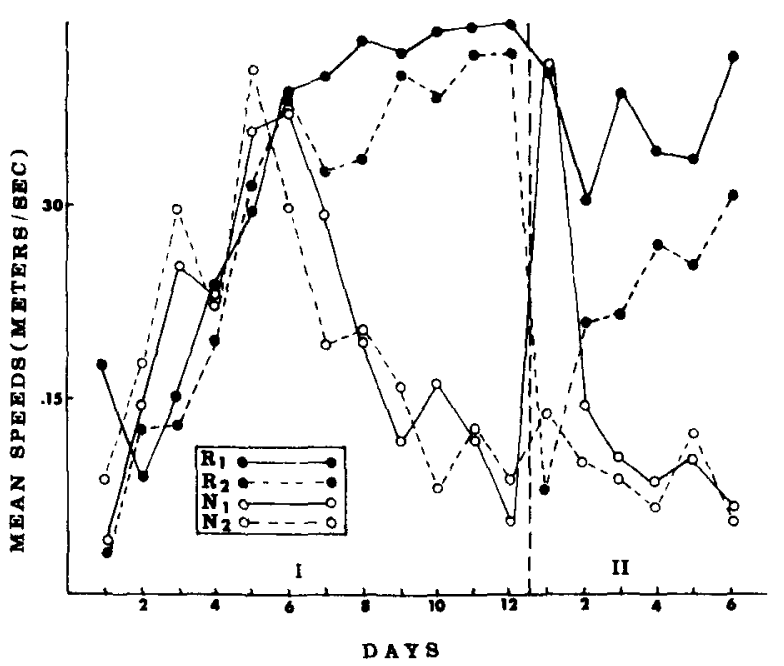

Figure 5. Mean goal speeds (meters/sec), Experiment II.

rational patterning appeared to have been established in both the run and goal measures, and asymptotic performance reached in the start measure). The results of these analyses indicated that the $\mathrm{R}$ vs. $\mathrm{N}$ factor was significant in the run $[\mathrm{F}(1,70)=16.21, \mathrm{p}<.01]$ and goal $[F(1,70)=57.96, p<.01]$ measures. No other significant effects were obtained. The statistical analyses support the graphical impressions that significant double-alternation patterning was established only in the run and goal measures during Phase 1.

Similar analyses performed on the Phase 2 data indicated that the $\mathrm{R}-\mathrm{N}$ by Days interaction was significant in the run $[F(5,109)=2.45, p<.05]$ and goal $[F(5,109)=4.89, p<.01]$ measures. Further tests (Tukey's procedure) indicated that a significant $R$ vs. $N$ difference $(p<.05)$ existed in the run measure only on Day 1 of Phase 2. However, significant $(p<.01)$ R vs. $\mathrm{N}$ differences were shown in the goal measure on Days 3-6 of Phase 2. Also, the R vs. N factor was found to be significant in the goal measure $[F(1,109)=8.72, p<.01]$ during Phase 2 .

Tukey's procedure was also used to determine specific within-day effects in the run and goal measures on Day 12 of Phase 1 and Day 1 of Phase 2. These comparisons should give additional information about the effect of the shift in the Odor-Donor schedule (i.e., odor cues) and the concomitant change in Run subject performance. The results indicated that neither $R_{1}$ and $R_{2}$ nor $N_{1}$ and $N_{2}$ differed significantly from each other in either the run or goal measure on Day 12 of Phase 1 . However, on Day 1 of Phase $2 R_{1}$ was significantly $(p<.01)$ faster than $R_{2}$ in the run and goal measures, and $N_{1}$ was significantly $(p<.01)$ faster than $N_{2}$ in the goal measure.

When the locus of odor was moved to the midsection of the runway, the Run subjects developed patterning in the run and goal sections only. Negatively correlating the Odor-Donor and Run schedules 
(Phase 2) produced an immediate disruption of responding in the run and goal segments. More specifically, speed on Trial $\mathbf{R}_{2}$ (now preceded by $\mathrm{N}$ donors) was immediately depressed, and speed on Trial $\mathbf{N}_{\mathbf{2}}$ (now preceded by $\mathrm{R}$ donors) was immediately slevated. However, rational patterning returned in the goal segment, presumably due to the continued predictability of the odors emitted by previous Run subjects.

\section{GENERAL DISCUSSION}

The results indicate that the rat will readily use as cues the kind of odors that were established in these studies, and further, that it will utilize the first odors encountered so long as odors further down the response chain are redundant or nonpredictive.

An interesting question prompted by a closer consideration of the data is: To what extent are reward and nonreward odors different for different animals? This question is suggested by the relative ease with which the animals regained discrimination in Phase 2 of Experiment II in the goal measure, but not in the run measure, after odors in the run section had been reversed. The speed with which this discrimination was regained suggests that reward and nonreward odors may have been different for the Odor-Donor rats when compared with those of the Run rats. If the reward and nonreward odors had been the same for different animals, one might have expected the discrimination to be more difficult to reestablish because the Run subjects would have had to discriminate on the basis of the same odor in different loci (i.e., both in the run and goal sections) of the apparatus. However, if the odors were different, as they appear to be, then the discrimination would have been substantially easier in that the subject could discriminate different odors established in different loci.

Another interesting aspect of the data of Phase 2 (Experiment II) is the rapidity with which the odors exuded by the Run subjects were utilized as discriminative stimuli. These cues, which were initially redundant and apparently little used, judging from the inappropriate responding observed on Day 1 of Phase 2, were quickly employed (by Day 2 ) as predictive stimuli. Both the ease of regaining the discrimination in the goal measure and the rapid utilization of Run-subject odors suggest that the rat is very facile in using such cues, and, further, that the operation and use of these cues may be very subtle.

Finally, the results of our experiments do not negate the possible operation of "memory" (see Capaldi, 1971; Spear, 1971) as a factor in addition to odor cues. As previously mentioned, in Experiment I the next to last $\mathrm{N}$ trial of the day apparently became a cue signaling "time out" from reinforcement. This kind of effect is also suggested by the initial trials of Phase 2 in Experiment II. And it was also the case that reversing the cues (both experiments) had little effect upon performance on $R_{1}$ trials. In these instances, performance was not controlled to any great extent by odor cues, but more by those cues associated with the first trial of the day.

\section{REFERENCES}

Amsel, A., Hug, J. J., \& Surridge, C. T. Subject to subject tral sequence, odor trails, and patterning at 24-h ITI. Psychonomic Science, 1969, 15, 787.793.

Bloom, J. M., \& Phillips, J. M. Conspecific odors as discriminative stimuli in the rat. Behavioral Biology, 1973, 8, 279.283.

CAPAldi, E. J. Memory and learning: A sequential viewpoint. In W. K. Honig \& P. H. R. James (Eds.), Animal memory. New York and London: Academic Press, 1971. Pp. 111-154.

Collerain, I., \& Ludvigson, H. W. Aversion of conspecific odor of frustrative nonreward in rats. Psychonomic Science, 1972, 27, 54-56.

Davis, S. F. Heterogeneous squad composition, odor cues, and the partial reinforcement effect. Perceptual and Motor Skills, 1973, 36, 1163-1169.

Davis, S. F., \& Ludvigson. H. W. The "depression effect" and the problem of odor control. Psychonomic Science, 1969, 14, 193-194.

Davis, S. F., Prytula, R. E., Harper, W. E., Tucker, H. K., Lewis, C., \& Flood, L. Double-alternation runway performance as a function of inter- and intra-reinforcement odor cues. Psychological Reports, 1974, 35, 787.793.

Ludvigson, H. W. Runway behavior of the rat as a function of inter-subject reward contingencies and constancy of daily reward schedule. Psychonomic Science, 1969, 15, 41-43.

Ludvigson, H. W., \& Sytsma, D. The sweet smell of success: Apparent double alternation in the rat. Psychonomic Science, 1967, 9, 283-284.

Mellgren, R. L., Fouts, R. S., \& Martin, J, W. Approach and escape to conspecitic odors of reward and non-reward. Animal Learning \& Behavior, 1973, 1, 129-132.

Morrison, R. R.. \& Ludvigson, H. W. Discrimination by rats of conspecific odors of reward and nonreward. Science. 1970, 167. $904-905$

PRATT, L. K., \& LumvigSon. H. W. The role of odor in latent extinction. Psychonomic Science, 1970, 20, 189-190.

Prytula, R. E., Bridges, C. C., Anderson, H. R., \& HAYES, L. C. Partial reinforcement effect under odor control. Psychological Reports, 1972, 30, 215-221.

Prytula, R. E., \& Davis, S. F. Runway performance as a function of positively and negatively correlated olfactory cues. Psychological Reports, 1974, 35, 735-740.

Seago, J. D., Ludvigson, H. W., \& Remley, N. R. Effects of anosmia on apparent double-alternation in the rat. Journal of Comparative and Physiological Psychology, 1970, 71, 435-442.

SPEAR. N. E. Forgetting as retrieval failure. In W. K. Honig \& P. H. R. James (Eds.), Animal memory. New York and London: Academic Press, 1971. Pp. 45-109.

Wasserman, E. A., \& JENSEN, D. D. Olfactory stimuli and the "pseudo-extınction" effect. Science, 1969. 166. 1307-1309.

(Received for publication October 28, 1975; revision accepted May 13, 1976.) 